\section{International collaboration}

SIR - The Institute for Scientific Information (ISI) in Philadelphia recently reported in Science Watch (see Nature 379, 287; 1996) that "when one compares the percentage of internationally co-authored papers for 1992 against the figures for 1994, some of the countries have actually decreased their levels of international collaboration"1. As well

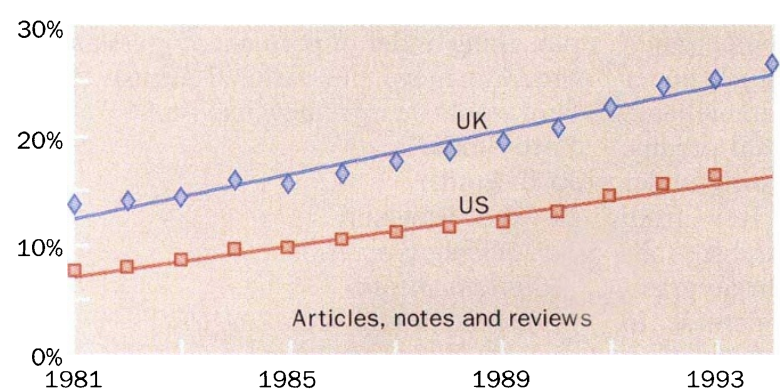

Percentage of UK and US SCI refereed publications with an international collaboration (sources: SPRU and $\mathrm{CHI}$ Research).

as scientific publications, Science Watch counted papers published in the social sciences and the arts and humanities indexed in their databases between 1981 and 1994. We wondered if declining trend in international collaboration would be found for more focused UK and US refereed papers in the natural and medical sciences.

We examined papers indexed in Science
Citation Index (SCI) data purchased on tape from ISI and thus excluding social science and arts and humanities publications. In addition, our analysis was restricted to articles, notes and review articles as these refereed publications most accurately reflect incremental contributions to the national and international innovation systems. Our results, therefore, are based on fewer papers; for example, in 1981 ISI counted 285,598 US papers while CHI Research, Inc. counted 134,769 US articles, notes and reviews in the natural and medical sciences $(63 \%$ papers fewer than ISI).

The figure shows our findings. In 1981, of the 134,769 papers having a US author, $7.5 \%$ (10,116 papers) also had a foreign author. As the graph shows, this trend grew steadily to $16.1 \%$ in 1993. Science Watch reported a possible decline in US international collaborations. However, both the ISI and CHI data suggest we will have to wait to see if the decline is a trend or an artefact.

The evidence from SPRU research contradicts the UK trend reported in Science Watch and suggests that the growth in international collaboration continues as reported earlier (see Nature $\mathbf{3 7 5}, \mathbf{9 9 ;}$ 1995) ${ }^{2}$. In 1981, of the 31,167 papers including a UK author, $13.7 \%$ (4,256 papers) also had a foreign author (4.6\% with European Union (EU), $4.5 \%$ with US). Science Watch reported a plateau between 1992 and 1994 of about $22-23 \%$ of papers having an international collaboration. In contrast, we found that international collaboration with UK scientists grew steadily to $26.5 \%$ in 1994 ( $10.5 \%$ with EU, $8.3 \%$ with US).

These findings suggest that international collaboration in refereed contributions to the various innovation systems may still be increasing while international cooperation may be on the decline in non-refereed science, social science and arts and humanities publications. We wonder if the same applies to other G7 nations?

\section{J. Sylvan Katz}

\section{Diana Hicks}

Science Policy Research Unit (SPRU),

University of Sussex,

Brighton, BN1 9RF, UK

Francis Narin

Kimberly Hamilton

CHI Research, Inc.,

10 White Horse Pike,

Haddon Heights,

New Jersey 08035, USA

1. Science Watch 7 (1), 1996.

2. Katz J. S. et al. Changing Shape of British Science Appendix C, 1995 (SPRU, University of Sussex).

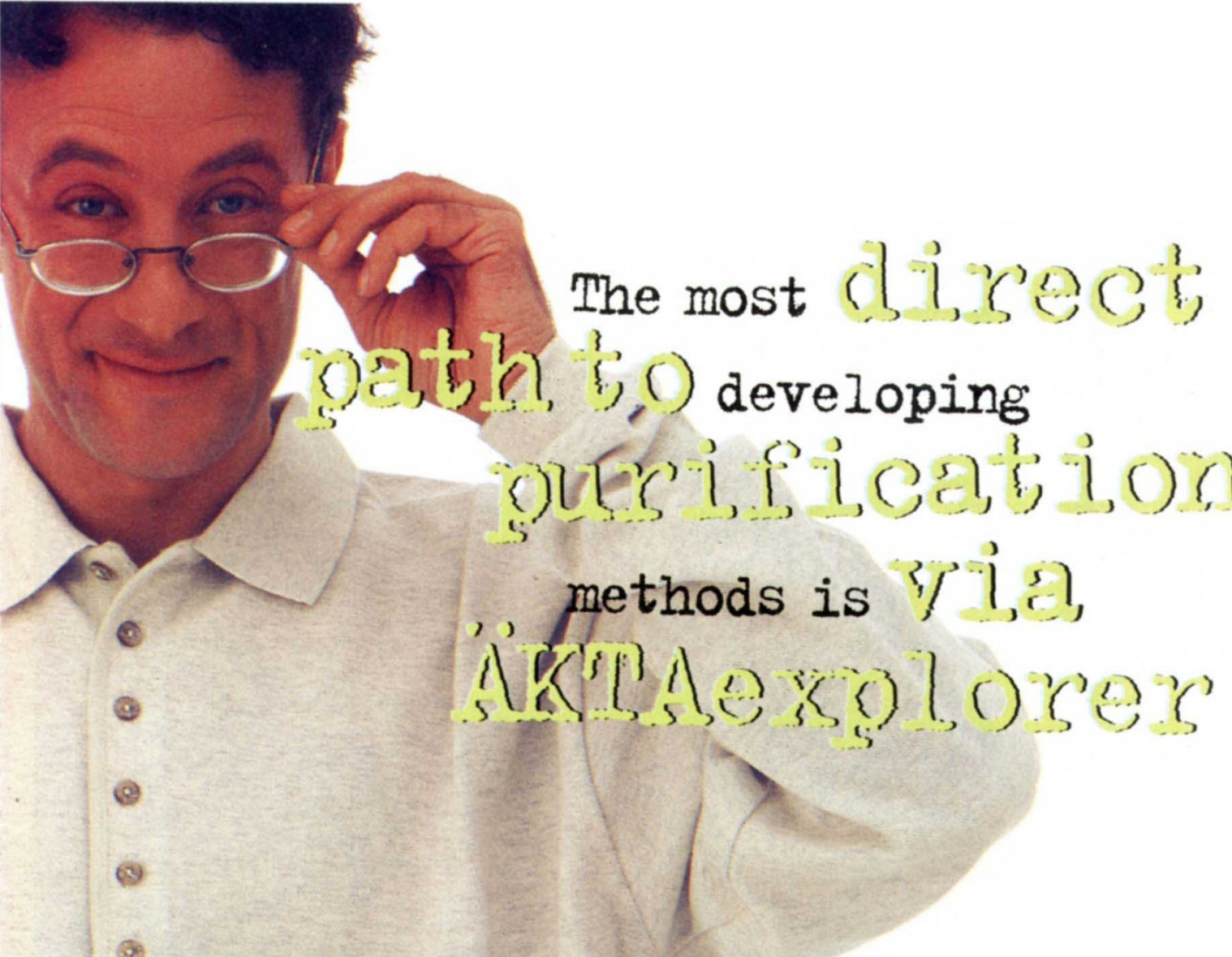

